\title{
Michael Sommer (ed.), Inter duo Imperia: Palmyra between East and West, (Oriens et Occidens, vol. 31), Franz Steiner Verlag, Stuttgart 2020, 167 pp. + b/w ills.; ISBN 978-3-515-12774-5
}

The number of studies concerning various aspects of the history and culture of Palmyra published in the last few years bear witness to scholars' continued interest in the rich past of this desert city. The volume Inter duo imperia: Palmyra between East and West contains papers presented at the conference "Palmyra. Orient. Okzident," which took place in Oldenburg in 2018. Its organiser, as well as the editor of the book in question, is Michael Sommer, a long-time researcher of Rome's eastern provinces and somebody who has dealt with the history of Palmyra at length in his works. The texts included in the volume were written by authors with an extensive output in the field of studies on Palmyra.

The book begins with an article by Sommer, "Inter duo imperia. The Palmyrenes between East and West" (pp. 9-21), essentially a comprehensive introduction. The author presents those issues of the history of Palmyra that have become the subject of numerous analyses and interpretations in recent years (Palmyra as a trading hub, Palmyra's culture as an effect of the influence of oriental and Greco-Roman culture traditions, and Palmyra's social and systemic institutions). It also provides a concise discussion of the contents of the other articles in the volume.

The history of Palmyra includes many periods about which little is known, but even those we do know more about have various mysteries. The reason for this, of course, is the number and state of preservation of historical sources. Despite their scarcity, researchers are by no means abandoning efforts to fill the gaps in our knowledge on Palmyra's past, using more sophisticated research methods to perform additional analysis of all historical evidence — both written and material. An example of this is Ted Kaizer's paper "Oasis-polis. Tadmur-Palmyra as a Greek city in the Roman world (or not) in five episodes" (pp. 23-36). This concerns five chapters from Palmyra's history which either contributed to its development or had a lesser or greater effect on its fate. Analysing them is useful in determining the extent to which Palmyra was a similar city to other urban centres of the Roman Empire, whose social and political life was based on a model characteristic of a typical Greek polis. This question has long been discussed by scholars as it is crucial for defining the nature of Palmyra's links with Rome and their influence on the form of its political system. The episodes in question were the presence of Germanicus in Palmyra and its consequences, Palmyra's economic development in the 2nd century CE, its acquisition of the status of colony, the city's political and military role in the second 
half of the 3rd century, and its fortunes after $275 \mathrm{CE}$. According to the author, Palmyra become a city like others in the Roman Empire only after its destruction by Emperor Aurelian. Although in the earlier phases of its history it demonstrated certain similarities to typical Greek polis, owing to its geographical location it was able to retain its cultural and specific social structure for a long time (p. 36). We must also agree with his view that Palmyra's acquisition of colony status, contrary to views that are expressed on this subject, ${ }^{1}$ did not have a visible impact on its fate (cf. p. 31 f.). This is shown by the fact that the Palmyrenes did not attach so much importance to the city's having this status as did the residents of other cities in the Roman Empire. The majority of epigraphic texts, including milestones in which Palmyra is referred to as a colony, were documents drawn up by the Roman administration. ${ }^{2}$ Furthermore, in the epigraphic evidence produced within Palmyra itself, the title of colony does not appear in Latin texts at all, and in Greek and Aramaic ones only a few times, mostly in inscriptions honouring eminent residents. ${ }^{3}$

The subject of Sommer's study is the circumstances that led to Palmyra becoming an important centre of long-distance trade ("Gateway Tadmur. The beginnings of Palmyra's long-distance trade," pp. 37-46). This issue is shown in a new light by the archaeological excavations which resulted in the discovery of remains of the so-called Hellenistic city, dated to the 2 nd century BCE. The ceramics unearthed during this dig show that at least from the mid-2nd century BCE, if not earlier, Palmyra had trade contacts with the cities of Syria. Unfortunately, at present it is difficult to determine how intensive these were and which centres they involved. What we do know, however, is that the dynamic development of trade contacts between Palmyra and the outside world ensued after the Parthian conquest of Mesopotamia. This is indicated by the considerably number of finds of Parthian glazed pottery at these excavations. Rome's control of Syria gave another impulse to the development of trade in Palmyra. Its inhabitants made full use of the merits of their city's location in an isolated oasis between two empires. The fact that they enjoyed the trust of their partners on both sides of the border also played a major role.

There are many indications that, despite the unfavourable climatic and geographical conditions resulting from scarcity of rainwater, an important sector of the economy for Palmyra was agriculture, which probably entirely satisfied the city's demand for cereal (cf. p. 63). Jørgen Christian Meyer's article presents issues concerning the role of agriculture in Palmyra's life ("Palmyra. Marginal agriculture in a marginal landscape?," pp. 47-63). Thanks to surviving elements of the agricultural infrastructure created by its residents, it is possible not only to locate areas of arable land, but also to reconstruct the form and character of installations used to provide water for agriculture. Farming on the territory of the city was possible mainly because the Palmyrenes set up a network of reservoirs, canals and dams built on a wadis that encircled the city. As a result, they were able to collect rainwater, and then to use it to irrigate the fields. The author notes

1 Cf. U. Hartmann, What is it like to be a Palmyrene in the age of crisis? Changing Palmyrene identities in the third century AD, in: A. Kropp, R. Raja (eds.), The World of Palmyra, Copenhagen 2016, 54-56.

2 See ibid., p. 54, note 6.

3 Cf. Inscriptions grecques et latines de la Syrie, vol. XVII,1: Palmyre, Beyrouth 2012, nos. 61, 65 and 224; F. Millar, The Roman Coloniae of the Near East: A Study of Cultural Relations, in: H. Solin \& M. Kajava (eds.), Roman Eastern Policy and Other Studies in Roman History: Proceedings of a Colloquium at Tvärminne 2-3 October 1987, Helsinki 1990, 44-46. 
that an important factor in the development of agriculture must have been the peaceful relations of the residents of Palmyra with the nomads living in the surrounding desert areas (pp. 62-63).

We know that Mesopotamia was the area of the greatest trading activity of the Palmyrene merchants, but definitely not the only one. The references to the presence of Palmyrenes in the area of the Red Sea and Egypt as well as southern Arabia and Socotra are analysed by Matthew A. Cobb ("Palmyrene Merchants and the Red Sea Trade," pp. 65-83). In his study, he tries to answer the question whether this presence was caused by the frequent wars in Mesopotamia between Rome and its eastern neighbour in the 3rd century CE, or by the search for alternative profitable trading options (pp. 65-66). Cobb argues that the reason for the Palmyrenes' appearance may have been the fact that units formed of Palmyrene soldiers were stationed there; to a certain extent, the possibility of doing good business was certainly also a factor, while the situation in Mesopotamia was less significant. Owing to the paucity of sources, however, it is impossible to draw any unequivocal conclusions on the nature of the Palmyrenes' presence both in Egypt and in the Red Sea basin (pp. 82-83). Unfortunately, I must add that the article, for some unknown reason, does not contain the maps and tables to which the author refers at various points (cf. p. 66 , note $6 ; 70$, note $34 ; 76$, note 63178 , note 71 ), and this prevents readers from following his arguments carefully.

Issues related to Palmyra's social history are reflected in the articles of Eivind Heldaas Seland ("The rise of the Merchant Prince? Scale, status, and wealth in Palmyrene trade," pp. 85-94) and Ann-Christine Sander ("On the edge of empire. Elite representation and identity building in Roman Palmyra," pp. 95-108). Both are about the social elites of the city, their transformations, the economic basis of their position in the city's social structure and their role in Palmyra's life, as well as the way they presented their position and built their prestige in public. There are many similarities between the conclusions drawn by the two authors. These provide a basis for generalisations on the nature of the Palmyrene social elites and the causes of changes within them over time. Starting from the 2 nd century CE, these elites were joined by people who owed their position not to aristocratic origin, but mainly to the effects of their own military and economic activity, which provided them with the support of the city and their fellow citizens. The significant role of members of the new elites was demonstrated by the fact that they raised new types of family gravestones in the form of towers, as well as displaying their military achievements in the public space. The picture of Palmyra's social elites from the period of the second and 3rd centuries CE that emerges from the sources suggests that they were markedly different from those we know from other regions of the Roman Empire. ${ }^{4}$

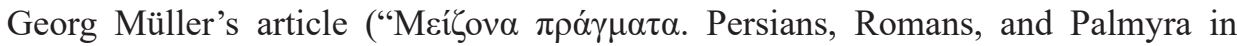
Zosimus' historiography," pp. 109-128) is also worthy of note. The author uses passages from Zosimus' work referring to Palmyra to show that the Roman historian discerned the

4 Cf. p. 108: "Unlike many other local elites across the Roman Empire (whose position depended on the convertibility of economic power into prestige), elite membership in Palmyra was based on flexible combinations of economic, political, social, and military power. Military power as a source of elite status was no usually fund in the Roman Empire's local elites of notable; it was a specific feature of the Palmyrene elite. Palmyra's ruling class was no leisure-class of notables, but rather represented themselves as frontier warriors, and economic, as well as political gatekeepers." 
city's role in the events in the East of the 260s and 270s CE. This is a rather idiosyncratic view, because Zosimus' presentation and evaluation of the facts is characterised by a distinctly unfavourable attitude towards the leaders of Palmyra, especially Zenobia, who were unable to bring the events they provoked under control, and therefore contributed to the Empire's worsening crisis.

The final article concerns the political and military situation in Syria in 2018. Its author is Alexander Will, a political scientist invited to present the events taking place in Syria at the time to the conference participants ("The political powers and Syria. War aims, scenarios and perspectives for a country in civil war," pp. 129-140). While this presentation was fully justified during the conference, its inclusion in this book is somewhat debatable. It is not just that the events depicted by Will are no longer current, but he also failed to address the fate of Palmyra and its monuments during the war that is described. This makes little sense in the context of the subject of the conference, which lent itself to discussing this issue. The dramatic consequences of the war in Palmyra are only given a brief mention in the book (pp. 18-19).

These critical remarks do not take away from the value of the work as a whole, which makes a significant contribution to knowledge on various aspects of the past of Palmyra - a city which, as M. Sommer rightly notes, has attracted broad interest as a result of its fate in recent years.

Edward Dąbrowa

(iD http:/orcid.org/0000-0002-9324-9096

Jagiellonian University in Kraków 